\title{
Investigating the Structurization Process of Iron Monosilicide Powders Obtained by High-Temperature Synthesis from the Preliminarily Mechanoactivated Burden
}

\author{
Vilena Hakob Martirosyan, Marine Eduard Sasuntsyan \\ Department of Chemical Technologies and Environmental Engineering, National Polytechnic University of \\ Armenia (NPUA), Yerevan, Armenia \\ Email: v.a.martirosyan@mail.ru,msasuntsyan@mail.ru
}

Received 18 January 2016; accepted 17 April 2016; published 20 April 2016

Copyright (C) 2016 by authors and Scientific Research Publishing Inc.

This work is licensed under the Creative Commons Attribution International License (CC BY).

http://creativecommons.org/licenses/by/4.0/

(c) (i) Open Access

\begin{abstract}
Raising the efficiency of production, for the most part depends on the use of secondary material resources, particularly such wastes as metallurgical slags of the operating plants. Huge quantity of such slags generates an urgent problem of their reasonable utilization with maximum extraction of valuable metals. The objective of the thesis is the development of an efficient technology for obtaining powder iron-monosilicon alloy by means of processing of iron and silicon containing dump slags on the basis of out-of-furnace aluminothermic reduction. Thus, structure of the obtained alloy strongly depends on the state of the initial slags, on their correlation and on the amount of components contained in the complement of the burden. The structurization processes of the iron powder-like silicide obtained by the method of self-propagating high-temperature synthesis of the preliminarily mechano activated burden are investigated. The combination of these two methods allows to form unique materials and alloys, significantly reducing the power expenditure by applying the exothermal effect of the reactions, and to obtain a product with special physico-chemical properties. The results of the investigation are to obtain monophase iron silicide by preliminary mechano-chemical activation of the burden, containing a mixture of wastes of a certain composition obtained from metallurgical production-the Alaverdi copper-smelting and the Yerevan molybdenum factories, as well as $\mathrm{KNO}_{3}$ and $\mathrm{CaO}$ by combined aluminothermal reduction in the SHS regime. By the X-ray fluorescent method of analysis, the structurization process of the obtained alloy is studied. It is shown that, at the expense of preliminary mechano-chemical activation of the burden, a finer and homogeneous structure of powder-like iron silicide is formed.
\end{abstract}

\section{Keywords}

Copper and Molybdenum Slag, Mechanical Activation, X-Ray-Fluorescent, Reduction, 


\section{Iron Silicide, Synthesis}

\section{Introduction}

The development of the economic basis of Armenia is directly related to both the creation and wide introduction of new types of materials with special properties and the development of new advanced methods for their obtaining. Such materials belong to the iron monosilicide powders showing magnetic and electric properties which can be used as an alloying additive in the production of electrical-sheet steels and silicon-containing alloys with special physico-chemical properties, as well as in microelectronics [1]. From that standpoint, organizing a power-saving technology for obtaining such a valuable alloying additive by utilizing the secondary wastes is an urgent problem.

A perspective method for obtaining powders is the mechanically activated self-propagating high-temperature synthesis (MASHS). The given method allows to form unique materials and alloys at a significant decrease in powder consumption by using the exothermal effects of reactions and does not require special complex equipment. By preliminary mechanical activation, it is possible to affect the structure of the reaction mixture and the SHS parameters purposefully, thus ensuring the opportunity of regulating the structure and the phase composition of the powders to be synthesized [2] [3]. However, the ways of obtaining powder-like iron silicide by changing the chemical route in the mechano-activated reaction mixtures have not been practically studied. At the same time, the combustion regime ensures great possibilities in the structure variation of the synthesized materials, while the SHS implementation in powder systems eases the grinding of the synthesis products and the extraction of the required fractions of powders [3]-[5].

\section{The Statement of the Problem and the Goals of Investigation}

The goal of the investigation is to obtain monophase iron silicide by preliminary mechano-chemical activation of the burden, containing a mixture of wastes of a certain composition obtained from metallurgical production: the Alaverdi copper-smelting and the Yerevan molybdenum factories, as well as $\mathrm{NaNO}_{3}$ and $\mathrm{CaO}$ by combined aluminothermal reduction in the SHS regime, and the study of structurization conditions of the obtained ferroalloys.

A perfect and rational way of obtaining iron silicide is the aluminothermal method, allowing to obtain that alloy by combined reduction of iron and silicon oxides present at the slags. The process of aluminothermal reduction of slags represents a SHS as a result of which, the amount of the produced power satisfies the self-arbitrary proceeding of the process and does not require heat expenditure from outside. That process can be implemented by the out-furnace method, being an advantage of this method [4] [5].

In case of need, $\mathrm{NaNO}_{3}$, whose aluminothermal reduction is exothermal and leads to the increase in the heat balance of the reduction process, can be added into the burden. As a slag-forming additive, $\mathrm{CaO}$ is also added into the burden.

Due to high temperatures $(2500 \ldots 3000 \mathrm{~K})$, obtained in the SHS process, the burden seems to be boiling. Under these conditions, iron and silicon are reduced and, dissolving, form ferrosilicium, while the mixed oxides ( $\mathrm{MgO}, \mathrm{CaO}, \mathrm{Na}_{2} \mathrm{O}, \mathrm{Al}_{2} \mathrm{O}_{3}$ ) contained in the burden, form difficult-to-dissolve slags, which, after cooling is easily separated from the metallic phase. To provide such heating conditions in the thin layer of a solid substance by an external heating source of power is quite difficult or almost impossible. The extreme conditions mentioned above determine the advantage of the SHS process [6] [7].

\section{Materials and Methods of Investigation}

To measure the slag parameters, the converter and dump slags of the Alaverdi copper-smelting factory and the molybdenum slag of the Yerevan Pure Iron Plant were used. According to the data of the chemical analysis, the element composition (by metals) of the copper waste is the following: $44.59 \% \mathrm{Fe}$ and $17.5 \% \mathrm{Si}$ in the dump slags and $47.95 \% \mathrm{Fe}$ and $10.10 \% \mathrm{Si}$ in converter slags. The element composition of the molybdenum slag is $8.75 \% \mathrm{Fe}$ and $32.11 \% \mathrm{Si}$.

Investigation of the phase composition was carried out on the X-ray Diffractometer (DRON-3) in $\mathrm{Cu}_{\mathrm{k} \alpha}$ radia- 
tion. X-Ray technique was carried out in continuous mode within the interval of angles $2 \theta=10^{\circ} \ldots 90^{\circ}[8]$.

Investigation of the element composition of samples (by oxides) was conducted on the certified X-ray fluorescent spectrometer ED 2000 of "Oxford Instruments Analytical" Company (Great Britain) [7] [8].

The morphology of the cover surface was studied on the high-resolution electronic scanning microscope Mira of Tescan Company (Czech Republic) using a microroentgenospectral analyzer INCA Energy 350. To investigate the distribution of the elements over the surface, photography in the characteristic X-ray radiation was applied [9] [10].

The lower part is filled with quartz sand; the upper part is an open-top conical cap. In the middle of the experiments were carried out in the reactor (see Figure 1(a)), representing a metallic reservoir, consisting of two parts.

The lower part of the reactor, in the quartz sand a deepening was made where the burden sample consisting of initial mixtures of stoichiometric composition was placed and covered with the conical cap. In the center of the sample, the initiator $\left(\mathrm{Fe}_{3} \mathrm{O}_{4}+\mathrm{C}\right)$ was filled. The combustion was carried out by means of hot electric tungsten spiral from the upper end of the sample. Under these conditions, in the surface layers of the mixture, a chemical reaction arises, and a combustion wave is formed, propagating at a constant rate along the whole sample, i.e. SHS takes place. The combustion proceeds for 10 - 15 seconds in the temperature range of $2300-2500$ (K). After cooling, the combustion products form metallic (see Figure 1(b)) and slag (see Figure 1(c)) phases. At that, the metallic phase represents a solid piece that gathers at the bottom of the slag and is easily separated from it. After weighing, the metallic and slag phases were subjected to chemical (determination of iron and chromium content) and X-ray phase analyses.

The material and heat balance of the burden are introduced. The amounts of burden components are determined for slag processing. In accordance with these calculations, the burden should consist of converter or dump slags of aluminium powder, $\mathrm{NaNO}_{3}$ and $\mathrm{CaO}$. The calculated specific heat of the process was equivalent to $90 \mathrm{~kJ} / \mathrm{mole}$.

\section{The Experiment Results and Their Discussion}

The following samples have been investigated:

- Samples No. 1 - 4: the products of the aluminothermal reduction of mixtures, whose initial composition in shown in Table 1;

- Sample No. 5: standard ferrosilicium.

Since the dump and converter slags differ from each other by the content of iron and silicon, for comparison, burdens with dump and converter slags were prepared separately in case of previously selected optimal conditions and after 60 minutes of mechanical activation in the vibromill of the type M 30.

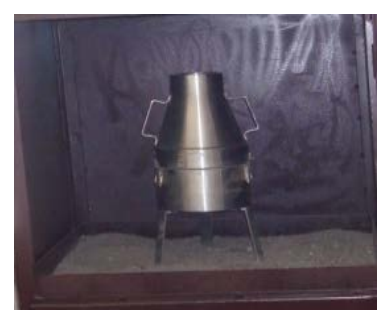

(a)

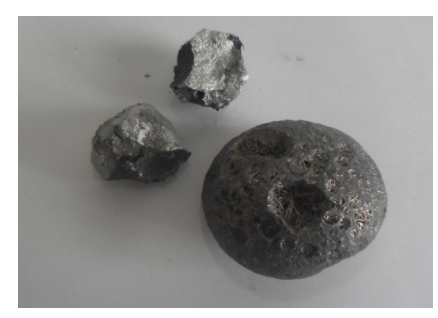

(b)

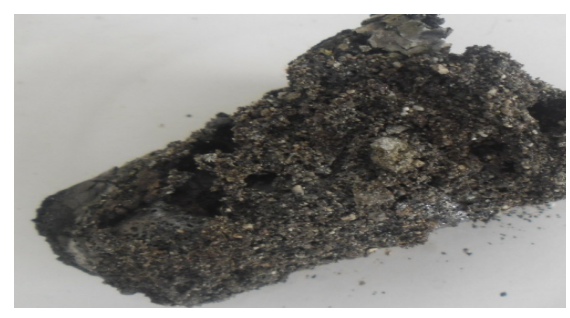

(c)

Figure 1. Laboratory SHS installation (a), metallic (b) and slag (c) phases.

Table 1. Numbering of burden for SHS reduction.

\begin{tabular}{|c|c|c|c|c|c|}
\hline \multirow{2}{*}{ Sample } & \multicolumn{5}{|c|}{ Composition of mixture, $g$} \\
\hline & Conver./dump slag & Molyb-denium slag & $\mathrm{NaNO}_{3}$ & $\mathrm{CaO}$ & Al \\
\hline Sample No.1 & 10 (conver.) & 1.5 & 2.5 & 1.5 & 8 \\
\hline Sample No. 2 & 10 (conver.) & 1 & 2.5 & 1 & 8 \\
\hline Sample No. 3 & 10 (dump) & 1.5 & 2.5 & 1.5 & 8 \\
\hline Sample No. 4 & 10 (dump) & 1 & 2.5 & 1 & 8 \\
\hline
\end{tabular}


The results of X-ray fluorescent analysis of samples No. 1 - 4 are introduced in Table 2.

The element composition of Sample No. 5 is as follows: $\mathrm{Si}-74.7 \%, \mathrm{Fe}-13.22 \%, \mathrm{Al}-1.1 \%, \mathrm{Ca}-1.5 \%$. The data in the table show that by the content of iron and silicon, almost similar data are obtained in both samples. At that, in the dump slags, the content of iron and silicon in the metallic phase is relatively higher, while in the slaglower. At comparing the roentgenograms of samples No. 1 - 4 (see Figure 2), it is seen that the phases Si [27-1402] and FeSi Ferrsilicite [35-0822] exist in all samples. The main phase of sample No. 1 is FeSi [33-0020]-40\%, then come descending quantities- $\mathrm{Si}, \mathrm{FeSi}, \mathrm{Al}_{2} \mathrm{O}_{3}, \mathrm{AlFe}, \mathrm{CaTiO}_{3}, \mathrm{FeTiO}_{3}, \mathrm{FeSi}_{2}$. In Sample No. 2, the main phase is FeSi Ferrsilicite [35-0822], there are also $\mathrm{Si}$ [27-1402], $\mathrm{Fe}$ [06-0696], $\mathrm{FeSi}_{2}, \mathrm{SiO}_{2}$, as well as products of aluminothermal reduction of the type $\mathrm{Al}_{8} \mathrm{Fe}_{2} \mathrm{Si}_{,} \mathrm{Al}_{0.7} \mathrm{Fe}_{3} \mathrm{Si}_{0.3}$. The phase composition of Sample No. 3 represent FeSi Ferrsilicite [35-0822] and $\mathrm{Si}$ [27-1402], as well as $\mathrm{FeSi}_{2}$ Ferrodisilicite [35-0822], $\mathrm{SiO}_{2}$ [14-0654], $\mathrm{Al}_{2} \mathrm{O}_{3}, \mathrm{Al}_{0.5} \mathrm{Fe}_{3} \mathrm{Si}_{0.5}$ are also present. The phase composition of Sample No. 4 represents FeSi Ferrsilicite [35-0822] and $\mathrm{Si}$ [27-1402], as well as $\mathrm{FeSi}_{2}$ Ferrodisilicite [35-0822], $\mathrm{Al}_{0.7} \mathrm{Fe}_{3} \mathrm{Si}_{0.3}$. The phase composition of Sample No. 5 represents Si [27-1402], FeSi Ferrsilicite [35-0822], and Ferrodisilicite [35-0822], $\mathrm{FeSi}_{2} \cdot \mathrm{SiO}_{2}, \mathrm{Al}_{3} \mathrm{Fe}_{2} \mathrm{Si}_{3}$.

By the results of the phase analysis of sample No. 5 (standard ferrosilicium), it is seen (see Figure 3) that the main phases are $\mathrm{Si}$ [27-1402] and FeSi [35-0822] which make almost $98 \%$. The products of aluminothermal reduction of the type $\mathrm{Al}_{8} \mathrm{Fe}_{2} \mathrm{Si}_{,} \mathrm{Al}_{0.7} \mathrm{Fe}_{3} \mathrm{Si}_{0.3}$ are not available.

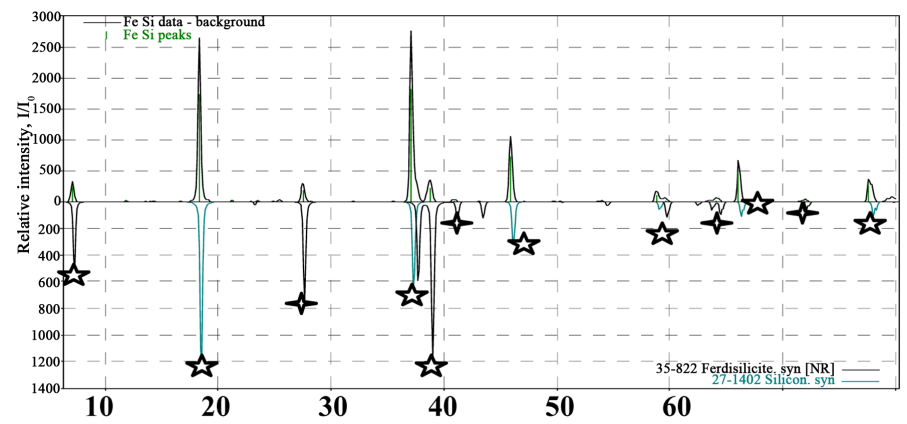

Figure 2. The result of decoding the roentgenograms of the Sample No. 5, where: $\nleftarrow-\mathrm{FeSi}, \diamond-\mathrm{Si}$.

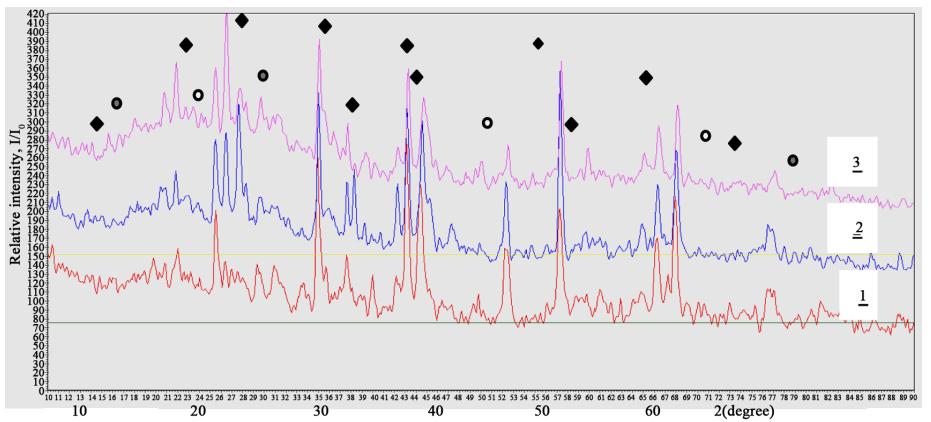

Figure 3. Comparison of the roentgenograms of the slag fraction of samples No. 1, 2 and 4, where: $\bullet-\mathrm{A}_{2} \mathrm{O}_{3} \mathrm{Corund}$, ०- $\mathrm{SiO}_{2}$ Cristobalite, o- $\mathrm{SiO}_{2}$ Quartsit.

Table 2. Element composition of samples No. 1 - 4.

\begin{tabular}{|c|c|c|c|c|c|c|c|c|}
\hline \multirow{3}{*}{ Elements } & \multicolumn{8}{|c|}{ Content of main elements, $\%$} \\
\hline & \multicolumn{2}{|c|}{ Sample No. 1} & \multicolumn{2}{|c|}{ Sample No. 2} & \multicolumn{2}{|c|}{ Sample No. 3} & \multicolumn{2}{|c|}{ Sample No. 4} \\
\hline & met. phase & slag phase & met. phase & slag phase & met. phase & slag phase & met. phase & slag phase \\
\hline $\mathbf{S i}$ & 20.7 & 9.1 & 19.8 & 8.8 & 22.1 & 5.6 & 19.2 & 4.0 \\
\hline $\mathrm{Fe}$ & 41.6 & 6.4 & 39.7 & 8.3 & 44.1 & 5.5 & 38.79 & 5.8 \\
\hline Al & 5.0 & 8.3 & 5.7 & 9.2 & 4.5 & 9.3 & 2.8 & 6.0 \\
\hline $\mathbf{T i}$ & 9.4 & 3.8 & 3.3 & 1.5 & 0.4 & 1.6 & 1.2 & 1.1 \\
\hline $\mathrm{Cu}$ & 1.4 & 0.8 & 1.7 & 1.9 & 0.1 & 0.6 & 1.3 & 0.6 \\
\hline $\mathbf{C a}$ & 0.8 & 3.8 & 0.6 & 2.9 & 1.9 & 0.2 & 0.7 & 4.3 \\
\hline
\end{tabular}


The phase composition of the slag fraction of samples No. 1, 2 and 4 are practically identical and represent $\mathrm{Al}_{2} \mathrm{O}_{3}$ [46-1212] Corundum, $\mathrm{SiO}_{2}$ Quartz and $\mathrm{SiO}_{2}$ Cristobalite, and small quantities of $\mathrm{FeSi}, \mathrm{Fe}_{3} \mathrm{Si}$ and $\mathrm{Fe}_{2} \mathrm{O}_{3}$ (Figure 4).

The phase composition of the slag fraction of samples No. 3 and 4, despite the identical composition of source mixtures, are quite different. The main phase of sample No. 4 is $\mathrm{Al}_{2} \mathrm{O}_{3}$ [46-1212] Corundum, as well as phases $\mathrm{SiO}_{2}$ Quartz, $\mathrm{SiO}_{2}$ Qristobalite, $\mathrm{Fe}$ and $\mathrm{Al}$ are present. In sample No. 3, the phase $\mathrm{Al}_{2} \mathrm{O}_{3}$ [46-1212] Corundum is not available, the main phase is $\mathrm{FeSi}, \mathrm{Si}$ and $\mathrm{AlFe}_{3}, \mathrm{Al}_{0.7} \mathrm{Fe}_{3} \mathrm{Si}_{0.3}, \mathrm{Al}_{0.7} \mathrm{Fe}_{3} \mathrm{Si}_{0.3}$, are present (see Figure 4).

In Figure 5 the morphology of the standard sample No. 5 is shown.

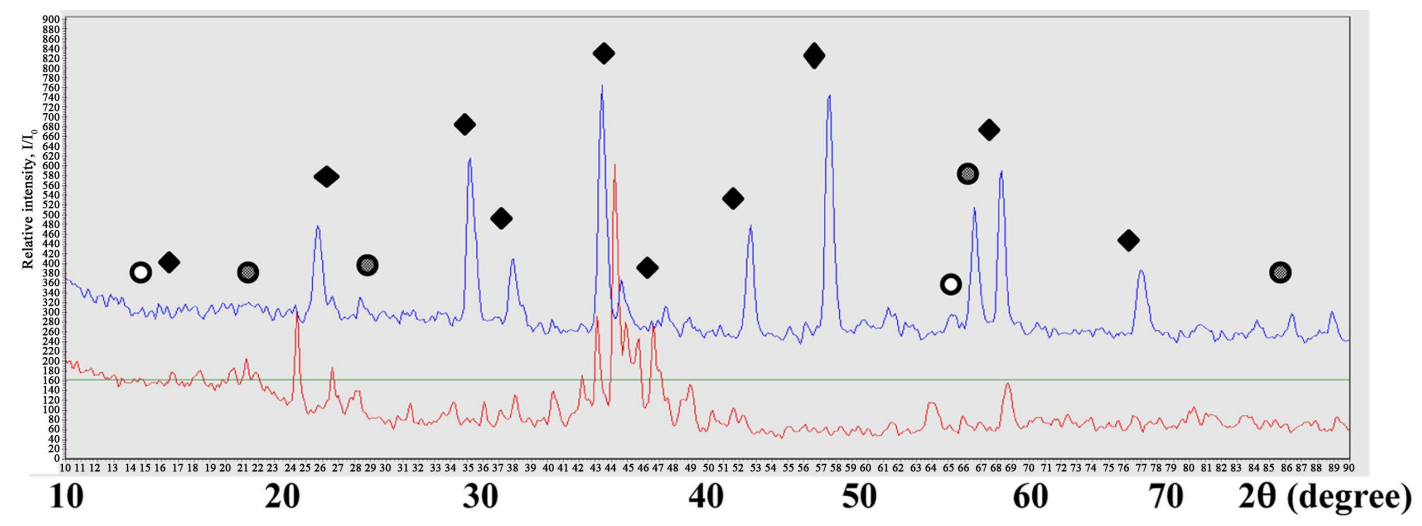

Figure 4. Comparison of the roentgenograms of slag fractions of samples No. 3 and 4 (from bottom to top), where: $\bullet-\mathrm{A}_{2} \mathrm{O}_{3}$ Corund, $\bullet-\mathrm{SiO}_{2}$ Cristobalite, o- $\mathrm{SiO}_{2}$ Quartsit.

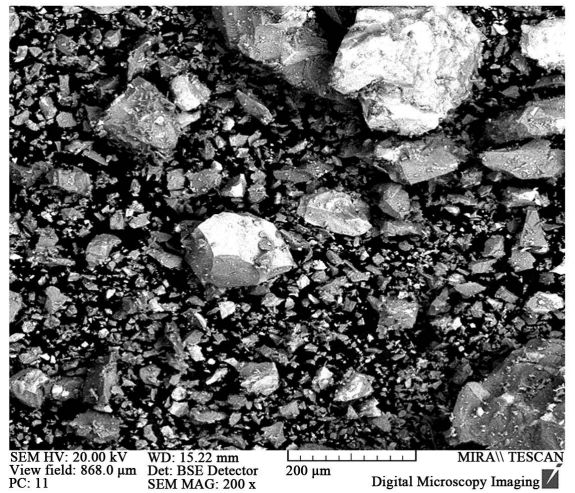

(a)

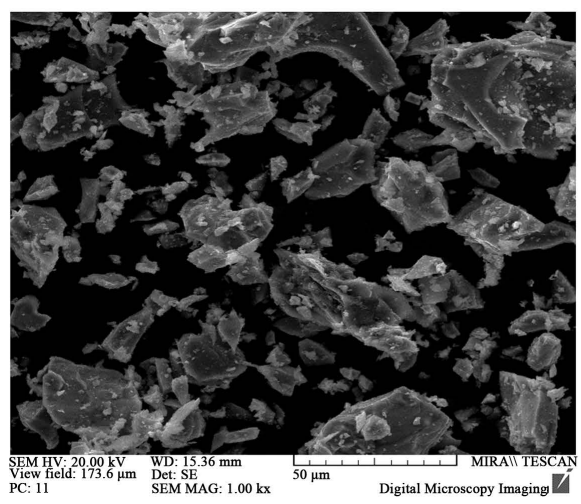

(c)

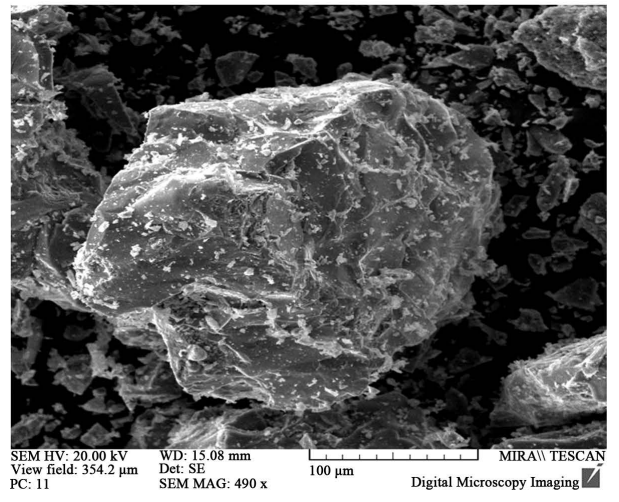

(b)

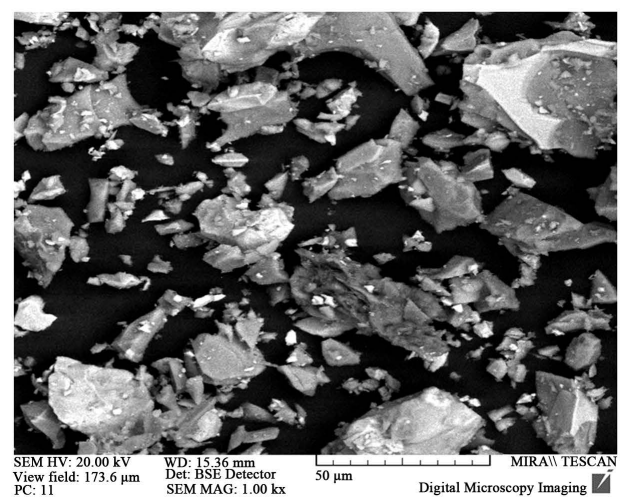

(d)

Figure 5. Morphology of the standard sample No. 5 (the light grey section is the phase containing FeSi, the dark grey section - the phase containing only Si). (a) $\times 200$; (b) $\times 500$; (c) $\times 3000$ (d) $\times 10,000$. 
Figure 6 shows that there are mainly two phases: the phase FeSi (the light grey section), and the phase containing only $\mathrm{Si}$ (the dark grey section). It is distinctly confirmed at enlargement (see Figure 7).

In Figures 8-11, the results of investigating the morphology of samples of metallic phases 1 - 4 are introduced.

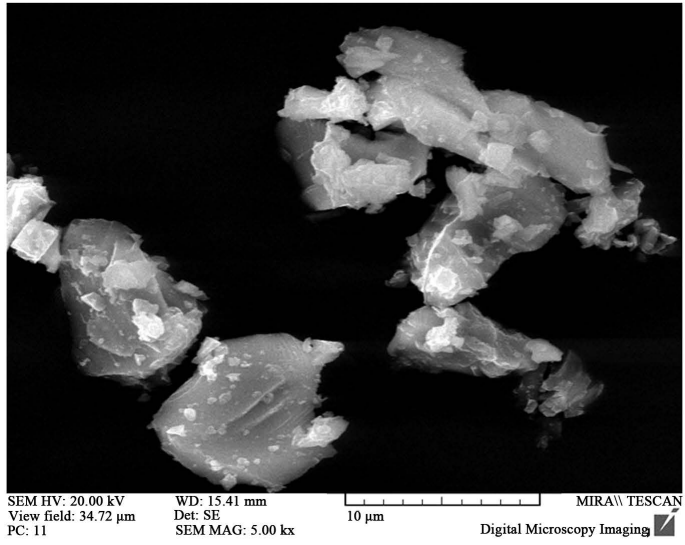

(a)

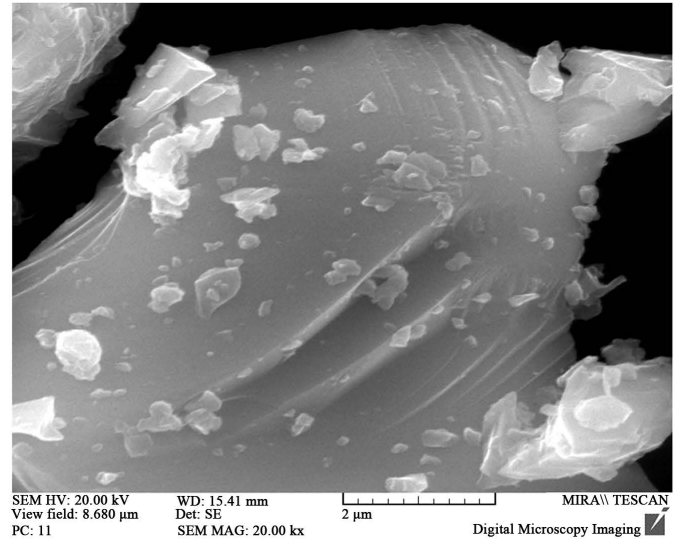

(b)

Figure 6. Morphology of sample No. 5. (a) $\times 5000$; (b) $\times 20,000$.

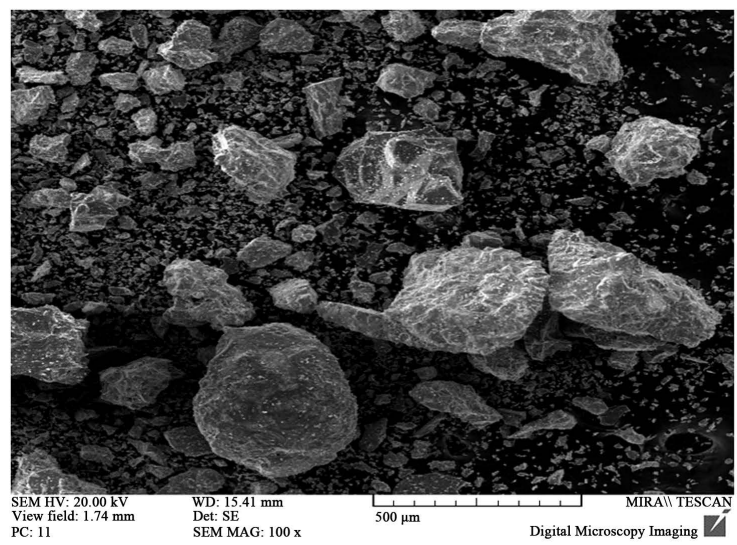

(a)

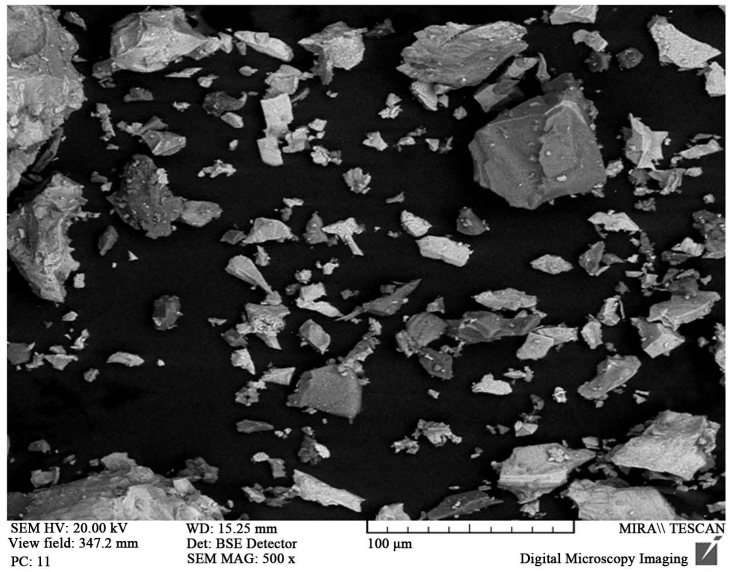

(c)

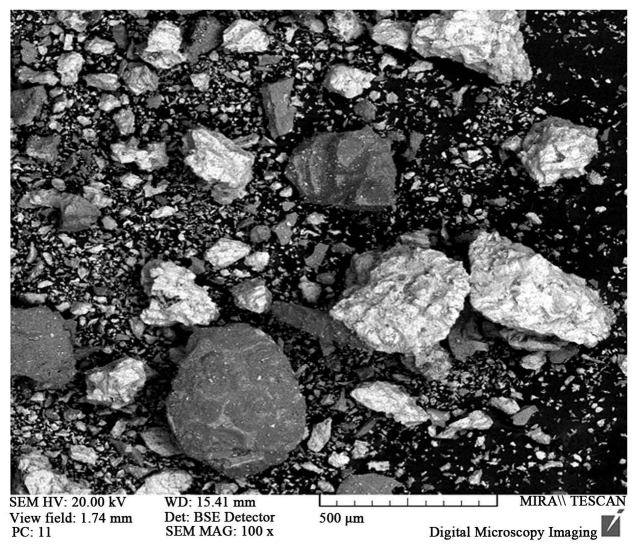

(b)

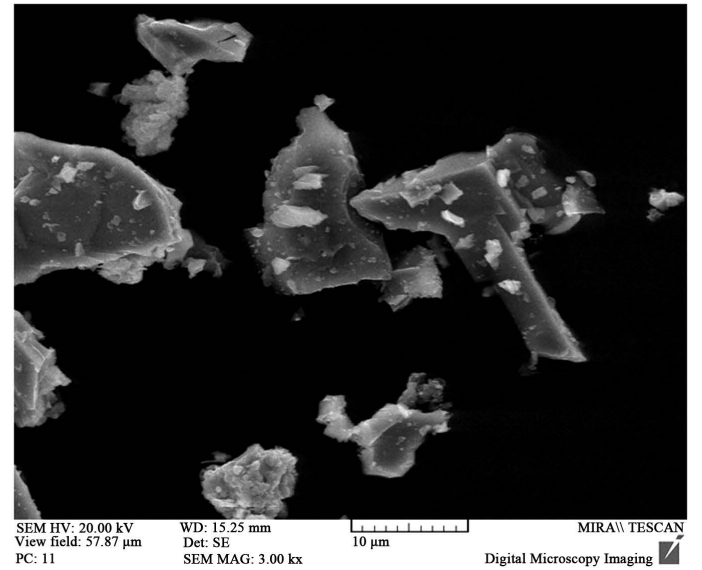

(d)

Figure 7. Morphology of sample No. 1 (metallic phase) (the light grey section is the phase containing FeSi, the dark grey section: the phase containing only Si). (a) $\times 200$; (b) $\times 500$; (c) $\times 3000$; (d) $\times 10,000$. 


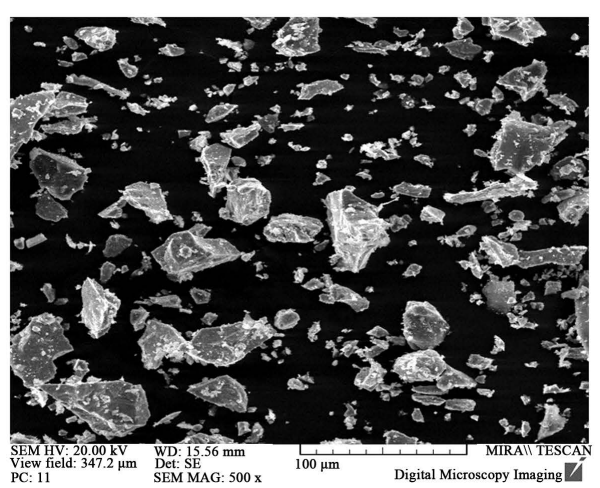

(a)

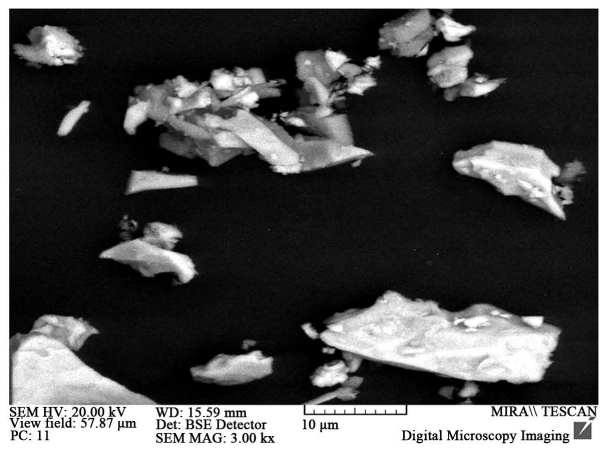

(c)

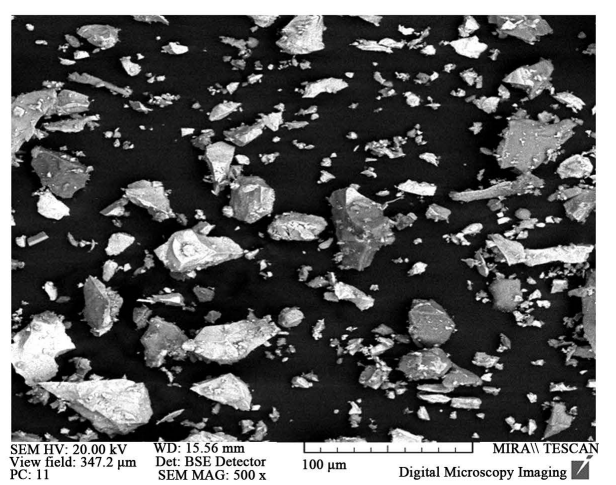

(b)

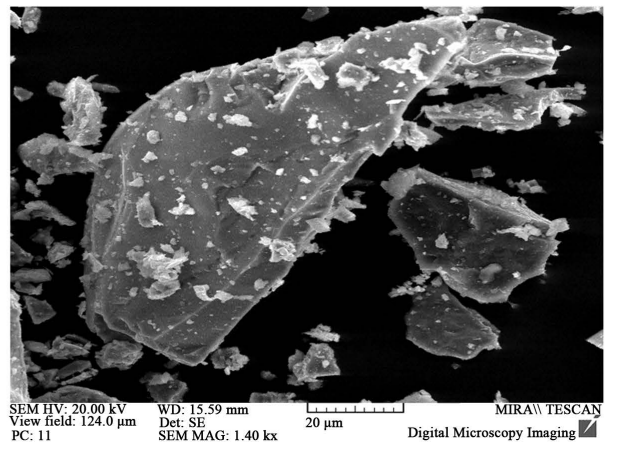

(d)

Figure 8. Morphology of sample No. 2 (metallic phase). (a) $\times 200$; (b) $\times 500$; (c) $\times 3000$; (d) $\times 10,000$.

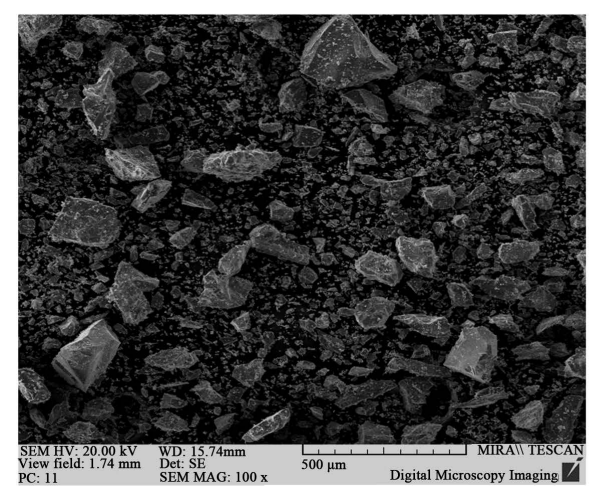

(a)

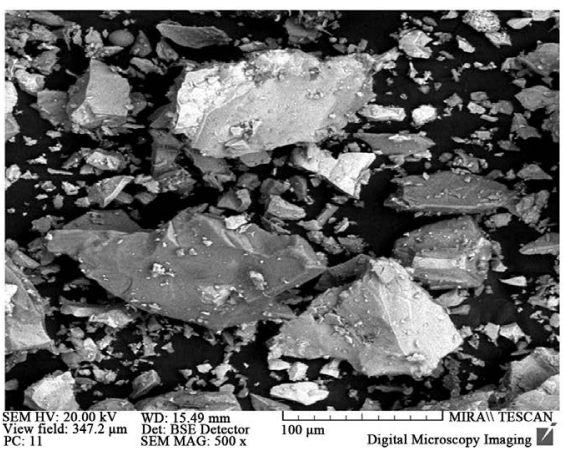

(c)

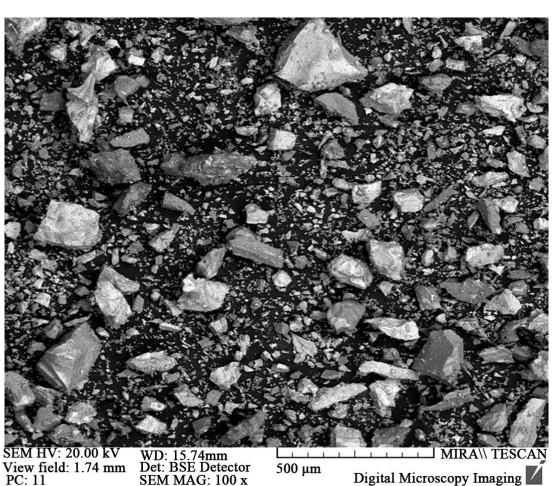

(b)

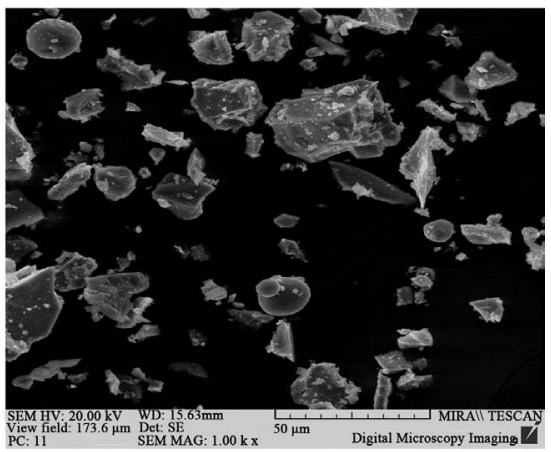

(d)

Figure 9. Morphology of sample No. 3 (metallic phase). (a) $\times 200$; (b) $\times 500$; (c) $\times 3000$; (d) $\times 10,000$. 


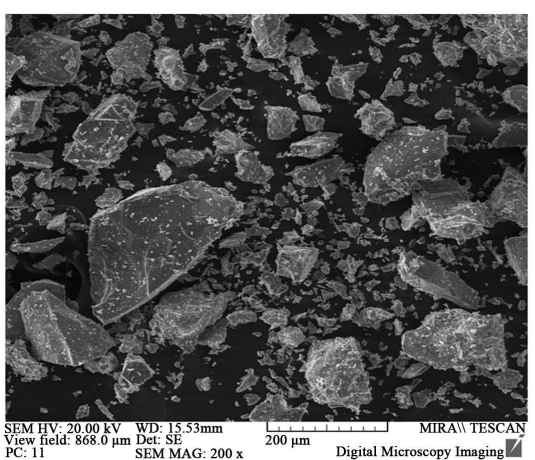

(a)

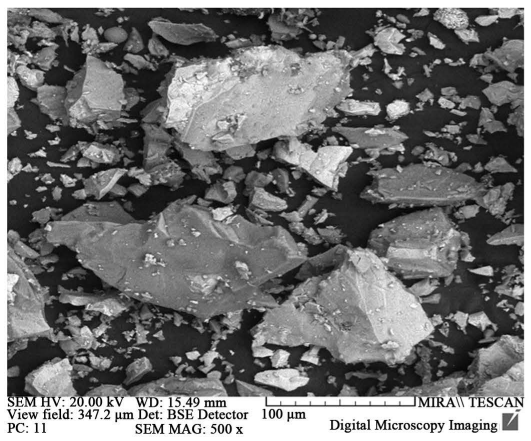

(c)

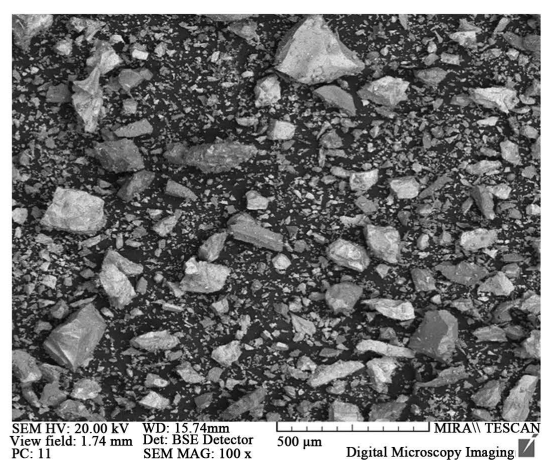

(b)

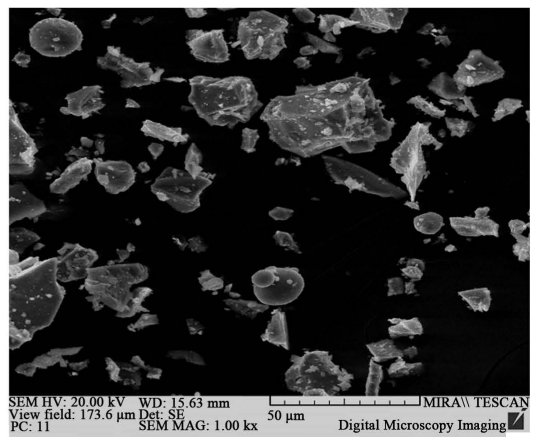

(d)

Figure 10. Morphology of sample No. 4 (metallic phase). (a) $\times 200$; (b) $\times 500$; (c) $\times 3000$; (d) $\times 10,000$.

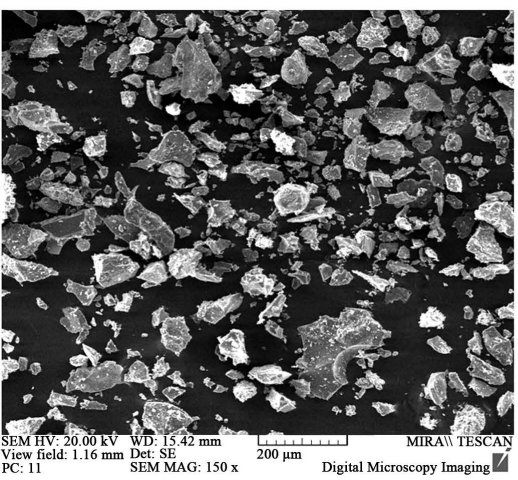

(a)

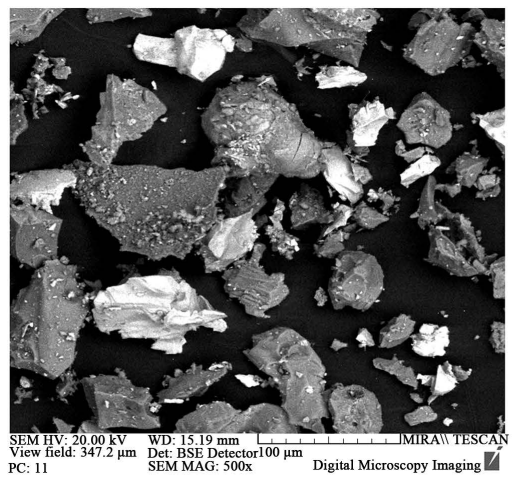

(c)

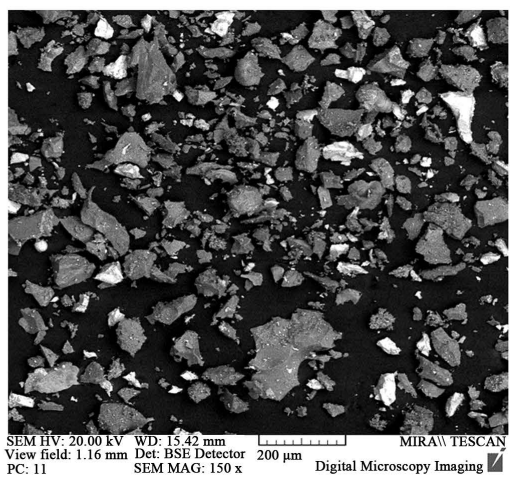

(b)

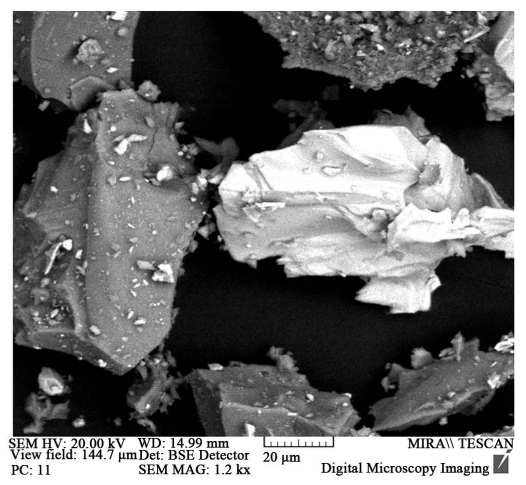

(d)

Figure 11. Morphology of sample No. 1 (slag phase). (a) $\times 200$; (b) $\times 500$; (c) $\times 3000$; (d) $\times 10,000$. 
On the morphological images, it can be seen that the structures of the metallic phase of FeSi obtained from the converter and dump slags, do not differ from each other notably, and both resemble the morphology of the standard sample. Only the structure of the metallic phase of FeSi obtained from converterand dump slags, is visibly contaminated with various minerals. In addition to light and dark grey shades, they have also visible fine shades of other minerals, but due to the preliminary mechanical activation of the burden, in all cases, thinner and more homogeneous structure of ferrosilicium is formed.

In Figures 11-14 the results of investigating the morphology of samples of slag phases 1 - 4 are introduced.

The images show that both the phase composition and morphology of the slag fraction of samples No. 3 and 4, despite the identic composition of the samples No. 1 and 2, essentially differ from each other, however, the main phase of all the samples are $\mathrm{Al}_{2} \mathrm{O}_{3}$ and $\mathrm{SiO}_{2}$.

\section{Conclusions}

After full recovery of $\mathrm{FeO}$ and $\mathrm{SiO}_{2}$, iron and silicon form a $\mathrm{FeSi}_{2}$. At the same time, if the iron is completely spent on education $\mathrm{FeSi}_{2}$, silicon remains in the excess, and forms the short-term phase $\mathrm{Fe}_{3} \mathrm{Si}_{2}, \mathrm{Fe}_{2} \mathrm{Si}_{5}$, and does not affect the formation of the main phase. Finally, as a result of these phases, reaction and ordering of silicon crystal lattice formed the most stable intermetalid FeSi. This is especially true for high temperatures. That's the reason why after the final cooling is homogeneous monosilicide $\mathrm{FeSi}$, its existence is confirmed by X-ray diffraction (Figures 7-10).

Summarizing the main regularities of formation of structure and phase composition of the iron-silicon powders by the SHS method, we can conclude that the preliminary mechanical activation of the reaction burden containing a mixture of waste of a particular composition obtained from metallurgical production in Alaverdi-

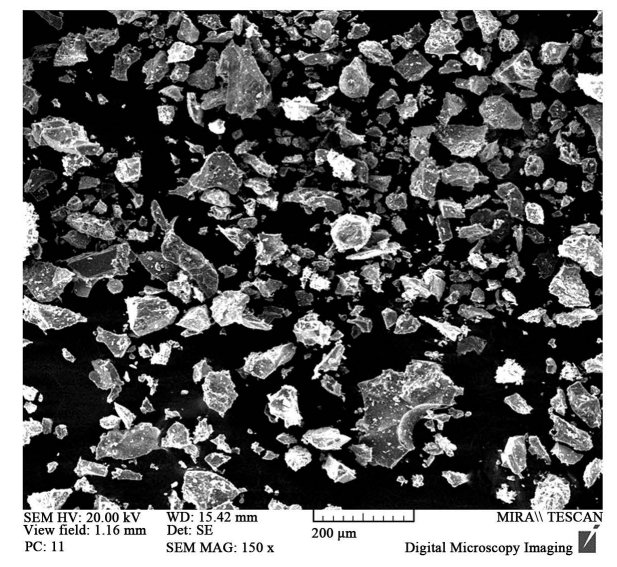

(a)

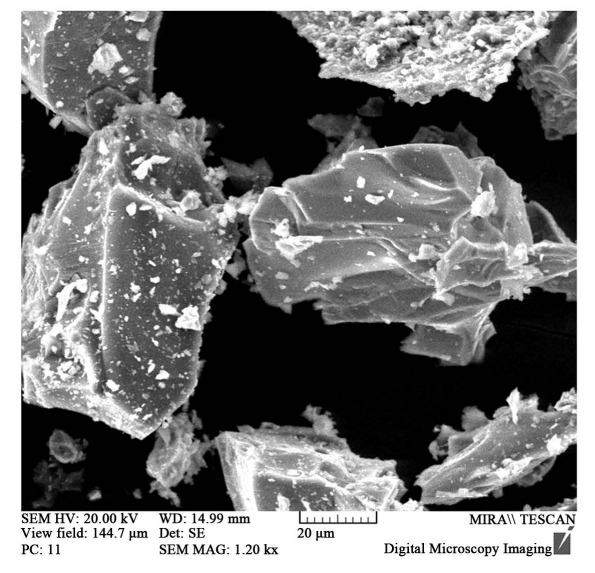

(c)

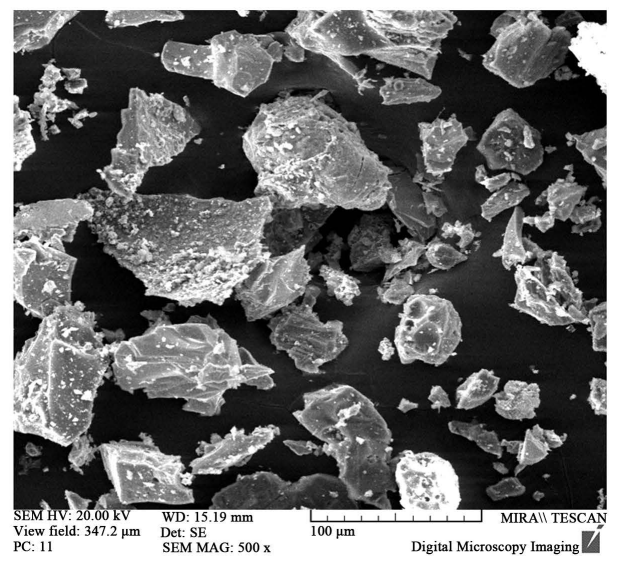

(b)

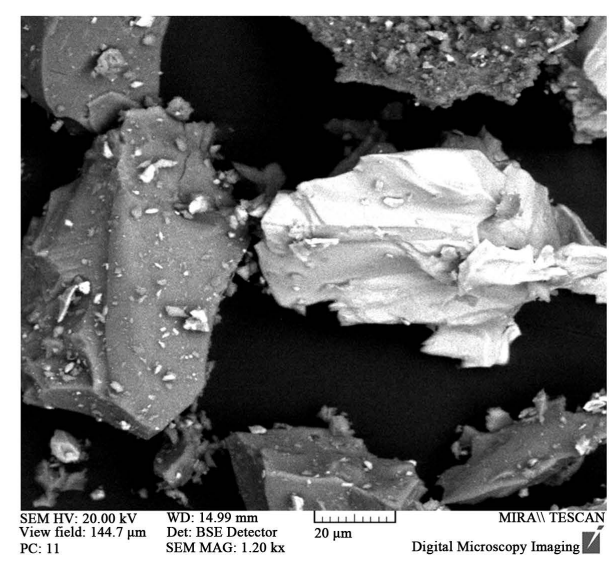

(d)

Figure 12. Morphology of sample No. 2 (slag phase). (a) $\times 200$; (b) $\times 500$; (c) $\times 3000$; (d) $\times 10,000$. 


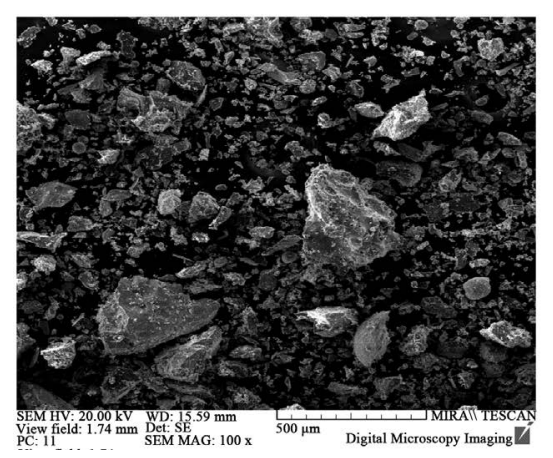

(a)

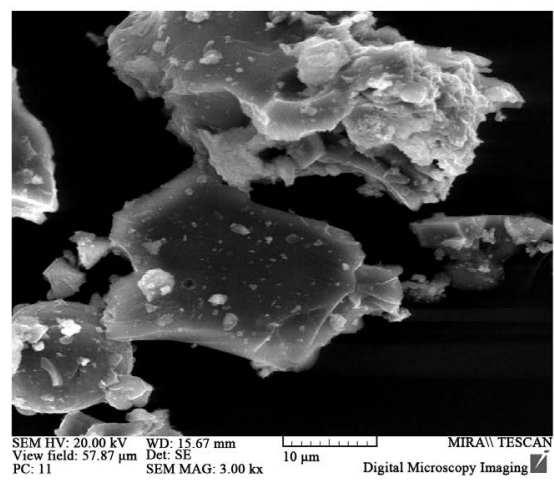

(c)

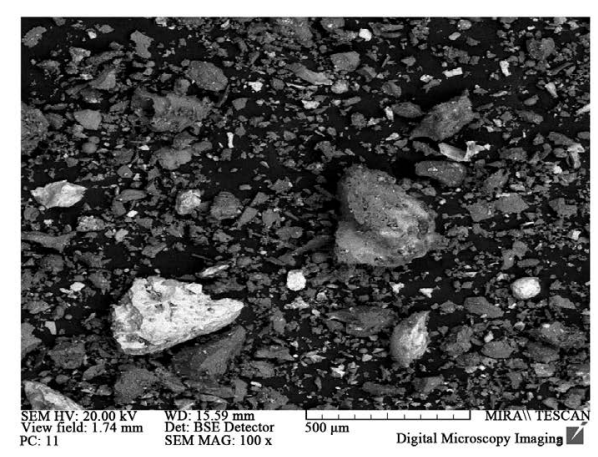

(b)

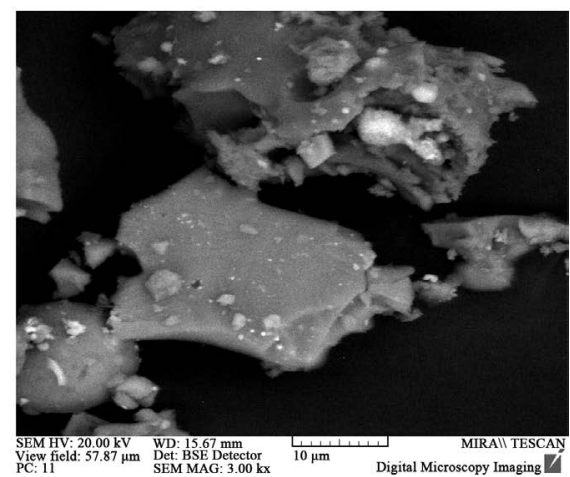

(d)

Figure 13. Morphology of sample No. 3 (slag phase). (a) $\times 200$; (b) $\times 500$; (c) $\times 3000$; (d) $\times 10,000$.

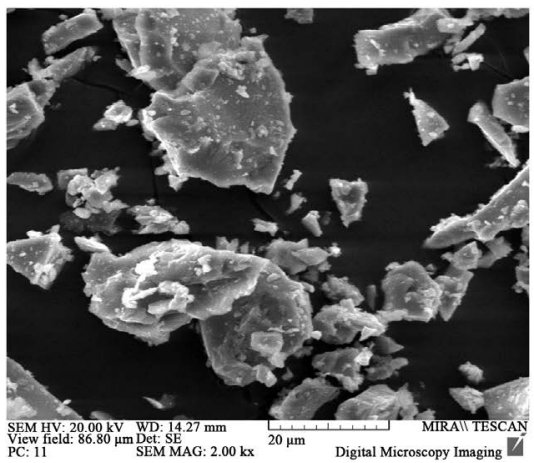

(a)

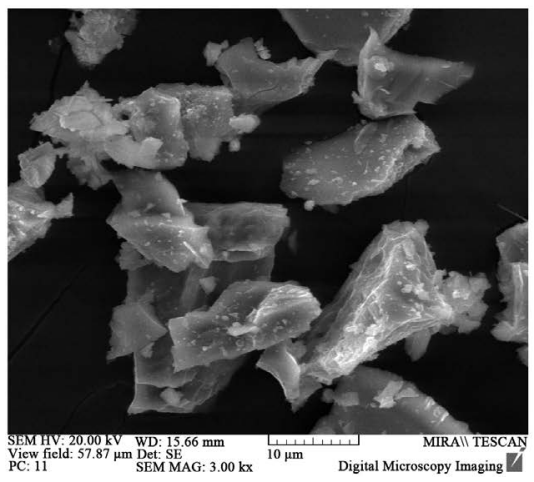

(c)

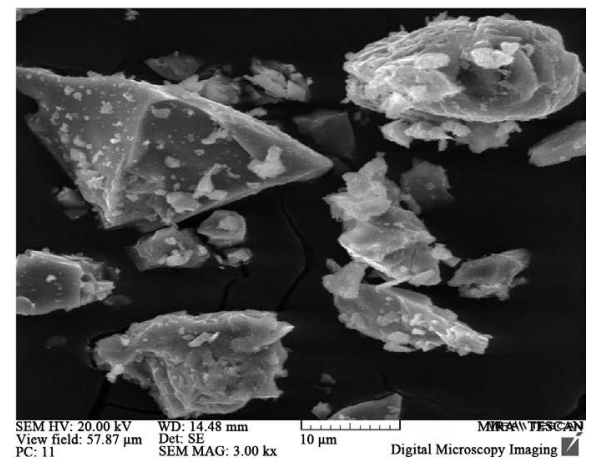

(b)

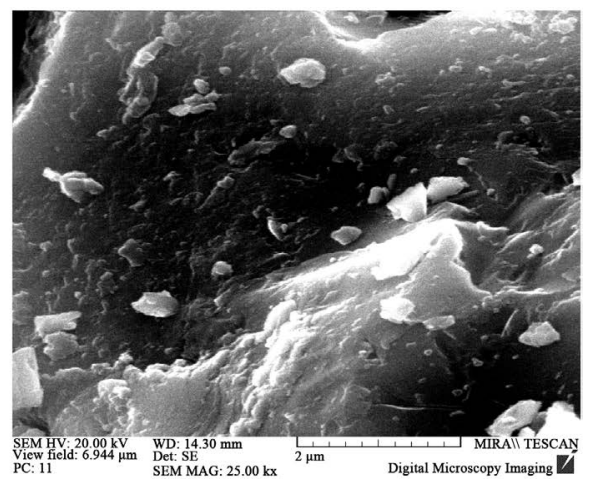

(d)

Figure 14. Morphology of sample No. 4 (slag phase). (a) $\times 200$; (b) $\times 500$; (c) $\times 3000$; (d) $\times 10,000$. 
copper-smelting and Yerevan molybdenum plants, as well as $\mathrm{KNO}_{3}$, and $\mathrm{CaO}$, in all cases allows to form a thinner and uniform product structure with increased depth of conversion. In further experiences these conclusions are confirmed [10] [11].

\section{Acknowledgements}

The investigation was carried out due to the financial support of the State Science Committee of RA Ministry of Science and Education in the framework of the Armenian-Belorussian joint scientific project No. 13 RB 049. The experimental data are obtaibed in the Belorussian State Scientific and Production Association of Powder Metallurgy.

\section{References}

[1] Belyaev, E.Y., Lomovsky, O.I. and Golubkov, G.V. (1998) Way of Receiving Thermoelectric Material on the Basis $\beta-\mathrm{FeSi}_{2}$. Patent RF No. 96116968/25.

[2] Letsko, A.K., Talako, T.H., Ilyushchenko, A.F., Grigorieva, T.F. and Lyakhov, N.Z. (2009) Mechanical Activation of the Charge for the SHS Iron Aluminide. Chemistry for Sustainable Development, 621-628. http://sibran.ru/en/journals/issue.php?ID=119880\&ARTICLE ID=129767

[3] Lyakhov, N.Z., Talako, T.L. and Grigoreva, T.F. (2008) Impact of the Mechanical Activation on the Processes of Phase and Structure Formation during Self-Propagating High-Temperature Synthesis. Editor-in-Chief O.I. Lomovski Novosibirsk, Parallel, Minsk, 168.

[4] Khina, B.B., Letsko, A., Talako, T.L., et al. (2005) Physical Mechanism of the Impact of the Mechanical Activation of Reaction Burden on the SHS. Powder Metallurgy: Republican Interdepartmental Collection of Scientific Works, 28, 94-98.

[5] Yukhvits, V.I. (2001) Self-Propagating High-Temperature Synthesis. Theory and Practice, Under the Editorship of Sichov A.E. Chernogolovka, Territory, 252.

[6] Avvakumov, E.G., Boldirev, V.V. and Kosobudski, I.D. (1972) Mechanical Activation of Solid-Phase Reactions. The Interaction of Pyrite with Iron. Preceedings of AS USSR, Series: Chemical Science, 4, 45-50.

[7] Durrer, R. and Folkert, G. (1976) Metallurgy of Ferroalloys. M. Metallurgy, 47.

[8] Revenko, A.G. (1994) X-Ray Spectral Fluorescence Analysis of Natural Materials. Novosibirsk, Science, 264.

[9] Pichugin, V.F., Yanovskiy, V.P., Morosova, N.S. and Yermolovich, I.M. (2010) Proceedings of the 10th International Conference on Modification of Materials with Particle Beams and Plasma Flows, Tomsk, 672-675.

[10] Philipova, N.A. (1975) Phase Analysis of Ores and Products of Their Processing. M. Chemistry, 280 p.

[11] Martirosyan, V.A., Sasuntsyan, M.E., Chitanyan, A.O., Nikoghosyan, A.S. and Talako, T.L. (2012) High-Temperature Synthesis of Ferrosilicon from Iron and Silicon-Containing Slag Production. Proceeding of SEUA, Series: Metallurgy, Material Science, Mining Engineering, 15, 19-27. 